\title{
Bridging the divide: the adjustment and decision-making experiences of people with dementia living with a recent diagnosis of cancer and its impact on family carers
}

\author{
Lorna McWilliams ${ }^{1}$, Caroline Swarbrick ${ }^{2}$, Janelle Yorke ${ }^{1,3}$, Lorraine Burgess ${ }^{4}$, Carole Farrell ${ }^{1}$, \\ Gunn Grande ${ }^{3}$, Sarah Bellhouse ${ }^{1}$ and John Keady ${ }^{2 *}$ \\ ${ }^{1}$ Christie Patient Centred Research, School of Oncology, The Christie NHS Foundation Trust, Manchester, \\ UK, ${ }^{2}$ Dementia and Ageing Research Team, Division of Nursing, Midwifery and Social Work, The \\ University of Manchester, Manchester, UK, ${ }^{3}$ Division of Nursing Midwifery and Social Work, School of \\ Health Sciences, The University of Manchester, Manchester, UK and ${ }^{4}$ The Christie NHS Foundation Trust, \\ Manchester, UK \\ ${ }^{*}$ Corresponding author. Email: John.Keady@manchester.ac.uk
}

(Accepted 21 September 2018; first published online 25 October 2018)

\begin{abstract}
The risk of living with dementia and, separately, cancer, increases exponentially with age. However, to date, there is a paucity of research investigating the experiences of people living with both these conditions. This study used semi-structured interviews to explore the decision-making and treatment options for people who live with both dementia and cancer. In total, ten people living with both dementia and cancer (aged 39-93 years) and nine family carers were interviewed. Braun and Clarke's approach to thematic analysis was used together with framework matrices to organise the data. In this article four sequential and descriptive themes are presented. 'Reaching a diagnosis of cancer' describes the vital role that family carers play in encouraging the person with dementia to seek an explanation for their presenting (undiagnosed cancer) symptoms to their general practitioner. 'Adjusting to the cancer diagnosis when living with dementia' outlines a variety of emotional and practical responses to receiving news of the diagnosis. 'Weighing up the cancer treatment options' highlights the different decisions and circumstances that family carers and people living with both dementia and cancer are faced with post-diagnosis. 'Undergoing cancer treatment' shares the finding that cancer treatment decision-making was not straightforward and that people living with both dementia and cancer would often forget about their cancer and what procedures they had been through.
\end{abstract}

Keywords: dementia; cancer; adjustment; decision-making; qualitative; experience; information

\section{Background}

Dementia is a terminal and neurodegenerative condition and an umbrella term for a number of diagnostic variants (Alzheimer's Society, 2015). Alzheimer's disease is

(C) Cambridge University Press 2018 
the most common condition in both older (i.e. 65 years and over) and younger (i.e. under the age of 65) people (Alzheimer's Research Trust, 2010; Alzheimer's Society, $2014 a, 2014 b$ ). Currently, in the United Kingdom (UK), there are approximately 850,000 people living with a dementia, a figure that is set to rise to over one million by 2021 (Alzheimer's Society, 2015). World-wide, 36 million people live with Alzheimer's disease or other dementias (Alzheimer's Disease International (ADI), 2013: 12). Increasing and advanced old age remains the most significant personal risk factor for developing a dementia-type illness (Alzheimer's Society, 2015), with one in four people over the age of 80 living with the condition (Alzheimer's Society, 2014a). The prevalence of dementia also intersects with gender as there are more women than men living with the condition and women are more likely to assume a care-giving role in the home and residential (e.g. care home) settings (Alzheimer's Society, 2014a; Erol et al., 2016). In the UK, around two-thirds of all people with dementia live at home (Alzheimer's Society, 2014a). Whilst there are positive experiences to be found in such situations (Nolan et al., 1996; La Fontaine et al., 2016), family carers of people living with dementia are exposed to the greatest degree of stress and burden as compared to caregiving groups of any other diagnostic condition (ADI, 2009).

Dementia is usually described as transitioning through early, middle and late/ advanced stages (World Health Organization, 2016), with people at the later end of the trajectory requiring support with most, and eventually all, of the activities of daily living (Alzheimer's Society, 2014a). Whilst a general consensus is emerging that end-of-life care for people living with dementia is best managed through a combination of clinical leadership, collaborative approaches, staff education and individualised person-centred care (Cahill et al., 2012), predicting the last days of life remains a challenge (ADI, 2016). Moreover, other than in rare instances, such as in the early identification and diagnosis of alcohol-related brain damage, the search for a restorative cure in Alzheimer's disease, vascular dementia and frontotemporal dementia, for example, continues. In recent years, and responding to the G8 pledge to find a treatment for dementia by 2025, the UK has seen the development of the Dementia Research Institutes led by basic science with the aim of advancing understanding on how the dementias develop and progress (for more information, see https://ukdri.ac.uk). However, much work remains to be done to develop effective treatments that give tangible hope to people living with a diagnosis of dementia that their signs and symptoms can be alleviated through the use of medication alone.

Progression through the stages of dementia is heterogeneous and prognosis is dependent upon a number of contextual factors, such as: the timing of a diagnosis across the trajectory of the condition, with an early diagnosis of dementia being a world-wide policy and practice imperative (ADI, 2011; see also Department of Health, 2012, 2015, 2016); the age of onset (Alzheimer's Research Trust, 2010); and the presence of any co-existing co-morbid condition(s), such as cardio-vascular problems (Bunn et al., 2014). This latter context was also noted in the All-Party Parliamentary Group on Dementia (APPG) report Dementia Rarely Travels Alone (APPG, 2016), which provided a salient reminder that around seven in ten people who live with a dementia also live with at least one other medical condition. Indeed, the report's authors made the bold, but arguably necessary assertion, that 
'managing multiple long-term conditions is the number one challenge for the health and social care services this century' (APPG, 2016: 15). Worryingly, a major health policy report by the ADI has suggested that people living with dementia are 'less likely to be admitted to hospital for interventional procedures that have the capacity to enhance quality of life' (2016: 60) and cancer care is included in the range of conditions to which this clear statement of health inequality applies.

Picking up on the previous point, the incidence of cancer is increasing annually, with 50 per cent of cancer diagnoses found in people aged over 70 (Cancer Research UK, 2017). At present, it is difficult to confirm the precise number of people diagnosed with dementia and cancer. A recent systematic review on this topic area by McWilliams et al. (2018) found significant variation in prevalence rates across a mixed evidence base, e.g. the highest combined dementia/cancer prevalence rates ranged from 32 to 45.6 per cent in hospice residents in the United States of America. In contrast, epidemiological studies report a pre-cancer diagnosis of dementia in cancer patients aged 68 years or older as 10 per cent for colon, 7.4 per cent for breast and 5.1 per cent for prostate patients (McWilliams et al., 2018). This is important as cancer treatment decision-making is complex and clinicians need to consider a range of issues, such as the site/stage of disease, biological prognostic factors, patients' performance status, comorbidities, social circumstances, choice of treatment modalities and potential adverse effects (Jalil et al., 2013). These issues become more challenging with older people given age-related decline in physical function, decreasing hepatic and renal function, increased polypharmacy, comorbidities and an increase in treatment toxicities (Bridges et al., 2015). Moreover, the complexity of communicating information and cancer treatment decision-making is heightened further when patients have a dementia due to the person's potential difficulties in understanding, and acting upon, information about the cancer diagnosis, treatment options and potential risks/benefits (Smebye et al., 2012; Taghizadeh and Österholm, 2014). Nevertheless, despite two recent reviews focusing on cancer and dementia (Hopkinson et al., 2016; McWilliams et al., 2018), including nine and 49 relevant studies, respectively, no single study included during the search process explored the lived experience of cancer and dementia.

Whilst there is limited social research in the field of people living with both dementia and cancer, an emerging body of work is beginning to appear since the two reviews were conducted. For example, Courtier et al. (2016) undertook a mixed qualitative methods study where everyday practices for people with cancer and self-identified memory loss/dementia were observed across four outpatient clinics at a single UK cancer centre. The design included people living with memory loss with and without capacity. In the overall study, a total of 30 observations were undertaken between October 2014 and February 2015, and the final patient interview sample comprised three women with breast cancer and seven men - four diagnosed with prostate cancer, two with head and neck cancers, and one with a pelvic malignancy. Three of these patients had a diagnosis of dementia. Interestingly, from the staff perspective, the reliability of the informant (person with self-identified memory loss/dementia) and their ability, or otherwise, to comply with complex treatment regimes became crucial issues in the treatment process. Accordingly, carers were reported in this study as being the 'key facilitators' for 
successful cancer consultations and management. Paradoxically, the authors then reported that the support needs of such carers were largely unrecognised and that staff were uncertain as to how to communicate effectively with patients who had memory difficulties (see also Trachsel et al., 2015).

This uncertainty and power imbalance in clinical decision-making in cancer care was also identified in an Australian study by Cook and McCarthy (2018). Here, Cook and McCarthy (2018) interviewed nine key staff members in a large cancer service and one of their key findings was that clinicians associated dementia with 'a lack of competence to understand the information provided'. A similar conclusion was reached in an exploratory UK study by Witham et al. (2014), where health-care workers from a regional oncology centre in the UK positioned people living with dementia and cancer as a vulnerable group but were uncertain as to what to do if vulnerability was identified and how it may then impact on their caring relationship.

To help further inform the field, this article attempts to build on this emerging literature by extending the numbers of people who live with both dementia and cancer and their family carers (where possible) within a qualitative study design and provides an exploratory thematic representation of lived experience. This article addresses the following two questions: (a) 'What is it like to live with dementia and then adjust to the experience of also living with cancer?' and (b) 'How are people who live with both dementia and cancer then involved in treatment decisionmaking, which may have curative potential for cancer?'

\section{Methods}

\section{Participants and setting}

A qualitative design using semi-structured interviews was used to explore the cancer and decision-making experiences of people who live with both dementia and cancer and their family carers. The study was set in a regional cancer centre (tertiary care) in North-West England serving a population of 3.2 million people. Purposeful sampling was used to identify participants with a confirmed dementia diagnosis known to the Macmillan dementia nurse consultant based at the hospital (LB in the authorship). LB was also able to give any additional support to participants should there be any distress from involvement. In the event, this was not called upon. Inclusion criteria were patients with: (a) any cancer type, (b) any stage and type of cancer treatment, and (c) any dementia type and severity. Family carers (if any present) were eligible to take part after the patient's consent had been confirmed; however, patients were able to participate should the family carer subsequently decline to take part or no family carer was identified.

\section{Procedure}

Prospective participants were approached by the Macmillan dementia nurse consultant (LB) who provided written study information and requested permission for one of the research and authorship team (LM) to initiate contact and answer questions about the study. As the research team were keen to involve people with dementia across the trajectory of the condition, the study followed the procedures prescribed by the Mental Capacity Act (Department of Health, 2005) for involving 
those who may lack capacity to consent. These procedures were operationalised through the guidance supplied by the British Psychological Society (2008) which helps researchers to comply with the nuances and requirements of the Mental Capacity Act (Department of Health, 2005), particularly on consent and recruitment into a study. As such, if it was deemed that a person with dementia lacked capacity to consent to the research then personal consultees were provided with information about the study. In the reported study, all personal consultees were family members who gave permission and written consent to the research team to approach the person with dementia about their involvement. If the person with both dementia and cancer subsequently consented to participate, their family member was also invited to take part in the study before making the necessary interview arrangements.

Interviews were conducted face-to-face in a quiet hospital room or in the patient's home. With consent, interviews were audio-recorded. Patient participants were given the choice of completing their interview alone or with a family carer. Family carers could support the patient interview and/or have a separate interview with one of the research team. Demographic and clinical information was collected from the medical notes, e.g. age and cancer treatment information. An interview topic guide was developed and questions focused on the experience of both dementia and cancer which included signs and symptoms of cancer, experience of diagnosis, treatment decision-making and cancer-related information needs. All but one (CF) of the interviews was conducted by LM, both postdoctoral researchers with experience of qualitative methods, continually discussing emerging findings and conceptual codes with co-authors. The sample of people who live with both dementia and cancer and their family carers is a sub-set of a larger study conducted by the authorship and reported elsewhere (McWilliams et al., 2018).

\section{Sample}

As shown in Table 1, the sample included people who live with both dementia and cancer $(\mathrm{N}=10)$ and family carers $(\mathrm{N}=9)$. All but two people who live with both dementia and cancer had a family member participate (plus two family members participated for one patient). Two people who lived with both dementia and cancer had capacity to give informed consent, and proxy consent was provided by a family member (personal consultee) for eight patients who lacked capacity. Verbal consent from the person living with dementia was received before any study procedures began. One other patient who lived with both dementia and cancer was invited to participate, however, the personal consultee did not consent for the researcher to approach the patient because of the patients' communication difficulties.

Of the eight audio-recorded patient interviews, five took place as a dyad and ranged from 46 to 62 minutes; patient-alone interviews $(\mathrm{N}=3)$ lasted 10-35 minutes. Family carer interviews lasted 26-49 minutes. Cancer disease groups included head and neck, colorectal, urology, skin, gynaecology and haematology. Nine patients had a pre-existing dementia diagnosis prior to attending the cancer hospital; one received a diagnosis of Alzheimer's disease during cancer treatment and was interviewed following completion of treatment. Other dementia diagnoses included Pick's disease, and vascular and AIDS-related dementia. Patients had been exposed 
Table 1. Sample characteristics

\begin{tabular}{|c|c|c|c|c|c|c|c|}
\hline $\begin{array}{l}\text { Case } \\
\text { number }\end{array}$ & Patient & Age & $\begin{array}{c}\text { Cancer site } \\
\text { (disease group) }\end{array}$ & $\begin{array}{l}\text { Stage of treatment } \\
\text { at time of interview }\end{array}$ & $\begin{array}{l}\text { Dementia diagnosis; } \\
\text { consent to interview }\end{array}$ & Family carer(s) & $\begin{array}{l}\text { Interview } \\
\text { type }\end{array}$ \\
\hline 1 & June & 76 & $\begin{array}{l}\text { Endometrium } \\
\text { (gynaecological) }\end{array}$ & Post-surgery & $\begin{array}{l}\text { Alzheimer's disease; able to } \\
\text { consent }\end{array}$ & Nick (husband) & $\begin{array}{l}\text { Patient/ } \\
\text { carer dyad }\end{array}$ \\
\hline 2 & Brenda & 60 & Anal (colorectal) & $\begin{array}{l}\text { Post-radiotherapy/ } \\
\text { chemotherapy }\end{array}$ & $\begin{array}{l}\text { Pick's disease; proxy consent } \\
\text { (personal consultee) }\end{array}$ & Steve (husband) & $\begin{array}{l}\text { Patient/ } \\
\text { carer dyad }\end{array}$ \\
\hline 3 & Sally & 83 & Larynx (head and neck) & Post-radiotherapy & $\begin{array}{l}\text { Mixed vascular and Alzheimer's } \\
\text { disease; proxy consent (personal } \\
\text { consultee) }\end{array}$ & Joe (son) & $\begin{array}{l}\text { Patient/ } \\
\text { carer dyad }\end{array}$ \\
\hline 4 & Joan & 73 & Bowel (colorectal) & $\begin{array}{l}\text { Post-radiotherapy (further } \\
\text { diagnostic testing) }\end{array}$ & $\begin{array}{l}\text { Mixed vascular and Alzheimer's } \\
\text { disease; proxy consent (personal } \\
\text { consultee) }\end{array}$ & $\begin{array}{l}\text { Darren (husband), } \\
\text { Sam (daughter) }\end{array}$ & $\begin{array}{l}\text { Patient/ } \\
\text { carer triad }\end{array}$ \\
\hline 5 & Joseph & 39 & Penis (urological) & $\begin{array}{l}\text { Post-surgery (further } \\
\text { diagnostic testing) }\end{array}$ & $\begin{array}{l}\text { HIV/AIDS-related dementia; able } \\
\text { to consent }\end{array}$ & Not applicable & Patient only \\
\hline 6 & Ben & 75 & Larynx (head and neck) & During radiotherapy & $\begin{array}{l}\text { Alzheimer's disease; proxy } \\
\text { consent (personal consultee) }\end{array}$ & Molly (daughter) & $\begin{array}{l}\text { Patient/ } \\
\text { carer dyad }\end{array}$ \\
\hline 9 & Alistair & 75 & $\begin{array}{l}\text { Bowel and liver } \\
\text { metastases (colorectal) }\end{array}$ & $\begin{array}{l}\text { Post-palliative } \\
\text { chemotherapy }\end{array}$ & $\begin{array}{l}\text { Alzheimer's disease; proxy } \\
\text { consent (personal consultee) }\end{array}$ & Maria (wife) & $\begin{array}{l}\text { Patient/ } \\
\text { carer dyad }\end{array}$ \\
\hline 10 & Agatha & 90 & Lip (head and neck) & $\begin{array}{l}\text { Post-decision not to have } \\
\text { treatment }\end{array}$ & $\begin{array}{l}\text { Vascular dementia; proxy } \\
\text { consent (personal consultee) }\end{array}$ & Billy (son) & $\begin{array}{l}\text { Patient/ } \\
\text { carer dyad }\end{array}$ \\
\hline
\end{tabular}


to a range of cancer treatments including radiotherapy, surgery, palliative chemotherapy and stem cell transplant. For one patient in the study sample, treatment was on-going, and for another, a best interests meeting had taken place for the person who lived with both dementia and cancer to have no cancer treatment at all. This will be returned to later in the article.

\section{Data analysis}

Interviews were audio-recorded, anonymised and transcribed verbatim; field notes were taken for each participant case (two patients refused to be audio-recorded and field notes were taken only). The data were analysed using Braun and Clarke's (2006) thematic approach and by means of framework matrices to organise the data, which allows for case comparison. Each transcript was read by a smaller analysis team (LM, SB, CS, JK) to get an overall sense of the data pre-coding. An agreed set of codes for the person who lives with both dementia and cancer and family carers were entered into the framework matrix for each of the two participant groups. On-going analysis and its interpretation were discussed at research management group meetings (i.e. all members of the authorship) when alternative explanations for emergent findings were suggested and discussed. The analysis focused on information needs and decision-making in the context of people who live with both dementia and cancer.

Data are presented as four overarching themes: (a) reaching a diagnosis of cancer; (b) adjusting to the cancer diagnosis when living with dementia; (c) weighing up the cancer treatment options; and (d) undergoing cancer treatment. All names appearing in the article are pseudonyms and the study received appropriate ethical approval (reference 16/YH/0156).

\section{Findings}

\section{Theme 1: Reaching a diagnosis of cancer}

Most family carers and people living with dementia spent a significant amount of time in the interview reflecting about how their, or the person living with dementia's, diagnosis of cancer was made. As the diagnosis of cancer for the majority was made at a point in time prior to the visit to the cancer treatment hospital, across the data-set, responsibility for making a decision to attend the individuals' general practitioner (GP) to investigate the presenting adverse physical symptom(s) was, in most cases, initiated by the family carer. For example, in Case 2, Brenda's husband, Steve, described himself as 'doing some detective work' having noticed that his wife was attempting to hide her rectal bleeding. As Steve went on to explain, the bleeding was present and noticeable in his wife's underwear, which he regularly placed in the couple's washing machine as part of his everyday caring duties. However, whilst Steve initially thought that this occurrence was 'odd' he did not immediately seek help from their GP for some six months as he thought that the bleeding was 'a woman's thing' and that it would 'simply stop'. Only the continuation of the bleeding and soiling over time led Steve to believe that something more serious was happening and the couple's GP was consulted. This step eventually led to the diagnosis of colorectal cancer. 
Similar 'detective stories' were shared by other family carers in the sample, with Billy (Case 10) believing that his mother's dementia played a significant role in the length of time it took to seek help, as he explained:

I still think it could have been spotted earlier on but it wouldn't have been so easy to spot with her picking it ... which I think might have been through the dementia.

However the decision to explore the presenting symptoms was reached, all participants living with dementia in this study were referred to the specialist cancer centre for further tests and investigations and, ultimately, faced with decisions about cancer treatment. At this point, the data shared some interesting insights into the procedures and practices that took place and how the experience of living with dementia intersected with the clinical test procedures. These diagnostic investigations take place most often at secondary care district hospitals before attending the cancer treatment hospital. For instance, Steve (Case 2) stated that his wife's diagnosis of dementia may have actually helped her to co-operate during what were intimate diagnostic investigations for colorectal cancer as, prior to her diagnosis of dementia, Brenda's main coping pattern over her lifecourse had been to ignore problems and hope that they would go away. Steve, therefore, put his wife's self-styled acceptance of the situation down to a 'blunting caused by the dementia' and a belief that 'the awareness wasn't really there of what was involved ... she just went with it and didn't seem at all worried'. It was clear that Steve displayed a strong sense of responsibility for assisting both the health-care practitioner and his wife during the course of her clinical investigations:

We had a lot of problems with her [Brenda] not keeping still during the scanning stages. We had one scan aborted and she wants me in the room with her to reassure her. There was a real need for me to be there at every point and every stage.

The situation was made more problematic as Steve felt that the health-care practitioner gave his wife 'very complicated instructions' during the cancer investigation phase. This simply fuelled Steve's need to be in the same space and time with his wife 'to break those instructions down into basic things', as he succinctly put it. Understandably, this was not a situation where patient privacy and confidentiality could be placed centre-stage.

In addition, Darren (Case 4), reflecting on his wife's investigative procedures at a secondary care hospital, suggested that health-care practitioners were not always confident in communicating with patients who had a dementia and made the telling observation that:

She had not a clue that nurse. She kept blaming her [Joan, person living with dementia] for moving but she didn't move. I don't think they [health-care practitioner] realise that she wants somebody with her when they're doing something. She wants somebody with her, rather than just staying in here [the clinical investigation room]. She's getting upset the whole time, waiting ... (pause) ... but 
anybody like her, I don't think they explain things properly. They don't realise that they [people living with dementia] can't take everything in. Not properly. They just told her what they told us.

Explanations about the steps necessary to reach a diagnosis of cancer were central to families as they were often uncertain about the process of taking consent for clinical investigations from someone who had a dementia. This uncertainty extended to knowing how much, or how little, they were to be involved in the clinical investigations consent process of their relative with dementia and what level of responsibility - if any - they shouldered in taking such a decision. Returning to Darren's (Case 4) experience, he believed that the health-care practitioners did not consider Joan's dementia to have any influence on her ability to understand and sign consent forms for procedures that she was about to undergo. However, this stood in stark contrast to his own understanding of this situation, a position drawn down from caring at home for his wife and knowledge of her cognitive functioning. Indeed, from the research team's perspective, and as Table 1 illustrates, Joan lacked the capacity to consent to an interview and required the personal consultee (Darren) to make that decision for her.

Managing steps to involvement and inclusion was important. As a person living with dementia, the language Joan (Case 4) used to explain her understandings and reflections about the biopsies that were continuing to take place post-diagnosis of her bowel cancer, was illuminating:

That woman who ran around and hurt me. Well, she didn't know what she were doing. 'No!' I kept saying to her. I said 'It's not right!' Two people hit at me. Well, I had to go on to, you know ... (pause) ... and eh, I don't, I weren't bothered about doing it ... (pause) ... but when she started, you know, she was ... (pause) ... at me weren't she? (turns to look at husband). So I was ... what's her name about that?

Whilst Joan's narrative may be fractured, the inherent meanings of her remembered and understood experiences can be clearly distilled from the words that she used to reflect on her clinical investigations. Moreover, the black-and-white words on this page do not do justice to the inflected emotions contained in some of the phrases (e.g. 'two people hit at me') and embodied movements that Joan performed during the telling of her story, such as contorting her face at certain points in time and (seemingly) wringing her hands with worry. For Joan, the shared and remembered stories were all about the pain and distress in undergoing highly personal and intimate clinical investigations. A similar experience was faced by Steve (Case 2) who shared that his wife, Brenda, would often ask staff 'if they were going to put a camera up her bottom'. Whilst such clinical investigative procedures were undoubtedly necessary, they provided moments of experience for people living with dementia where the meaning of the clinical intervention was not always understood at the time or remembered in a way that tied the clinical act to a helping procedure.

Across the data-set, for people living with dementia, it was the physical and emotional pain as well as personal invasion that seemed to hold most sway in the remembering and in the telling. 


\section{Theme 2: Adjusting to the cancer diagnosis when living with dementia}

The data-set also displayed a variety of responses to receiving the cancer diagnosis by people living with dementia. For example, Ben (Case 6), who received a diagnosis of head and neck cancer, reflected on the biographical connection of his diagnosis to that of his father who had also received the same diagnosis some years previously. However, Ben's father was not living with dementia at the time. As Ben shared during the interview, his father's diagnosis of head and neck cancer, and his eventual death, was 'a horrible time' in his life and this negative event, and association, affected him profoundly when he received exactly the same cancer type diagnosis. Ben made sense of this very challenging situation by acknowledging 'the relief that he felt in the improvements in cancer treatment and care in the present day as compared to his father's time. Other ways of adjusting to the cancer diagnosis when living with dementia included June (Case 1) who thought the 'whole thing was barmy' and that 'you've just got to get on with it'. A search for normalising everyday life appeared an important sense-making driver in such circumstances.

On the other hand, some family carers believed that the person they were caring for was either unaware that they had received a diagnosis of cancer or had simply forgotten what it was that they were told. As an illustration, Joe, Sally's son and family carer (Case 3 ), shared the following observation:

The doctor informed her [Sally, person living with dementia] that it was head and neck cancer ... well, she wasn't shocked at all or anything about it ... (pause) ... but then, I don't think she understood what the doctor was saying or what she had.

In an attempt to help his mother understand the seriousness of the diagnosis, Joe used the doctor's words at the time of the diagnosis when he communicated to Sally that she had a 'dirty throat'. It was rehearsing and reinforcing this direct correlation between the words 'dirty throat' and 'cancer' that Joe hoped his mother would understand and therefore identify with the seriousness of her situation. This creative strategy worked up to a point, with Joe explaining that his mother remembered on a few occasions that 'she has cancer' but then 'she lapses and it reverts back to really not knowing what's up with her'. Adjusting to a diagnosis of cancer when living with dementia had the potential, therefore, to not be a once-only event with families, and those with the diagnosis more specifically thrust into a fluctuating cycle of awareness and unawareness of disease states. Building on this point further, Alistair's cancer diagnosis (Case 9) was unexpected, despite a lengthy period of investigations for various health-related illnesses, as described by his wife Maria:

We got report after report, he's just 'an elderly man' and they couldn't find anything particularly wrong. I was very surprised to find that we were seeing the [cancer] specialist ... (pause) ... I was expecting something, but not that. When you've gone in thinking you are looking at a hernia ... it comes like a bolt from the blue.

During the interview, Alistair was unable to share his view on having cancer but it was clear that the diagnosis had caused a significant disruption to family 
functioning and adjustment, with Maria requiring a great deal of time during the interview to help her to share their story.

Such relational disruption carried through to the next theme, weighing up the treatment options, as the diagnosis of cancer, and its aetiology and prognosis, demanded further decisions to be taken by those at its centre: the person living with both dementia and cancer and their family member, informed by the cancer specialists and the health-care practitioners. Some of these decisions were to be taken immediately, some could be taken over time and some decision options were left open to have no treatment at all. For participants, each of these outcomes had their own states of emotional upheaval which varied from person to person and family to family.

\section{Theme 3: Weighing up the cancer treatment options}

Just as in dementia where the diagnosis acts as a critical juncture between a preand post-diagnostic identity (i.e. the diagnosis transitions you from a person without to a person with dementia and all the challenges that this label can then embody), the same reality exists in cancer, as seen in the previous theme heading. However, unlike in dementia, once a cancer diagnosis is made there are surgical interventions and medications that can potentially stem, reverse and cure the condition. Not for all cancers and not at all stages of a cancer diagnosis of course, but there is hope that the individual living with a diagnosis of cancer can return to a previous identity of being cancer-free and hold a future identity of being a 'cancer survivor' - an identity that engenders considerable compassion in society.

This potential to return to a healthy state from a diagnosis of cancer instigated the next step in the adjustment process, namely weighing up the cancer treatment options. This was not a straightforward process and many mentions were made of the word 'time' throughout the interviews when people who live with both dementia and cancer, and their family carers, were deciding what to do next. For instance, oncology doctors were asked to both 'slow down time' and 'to take more time' when offering choices in how to treat the cancer. As an illustration, Molly (Case 6) wanted more time in the treatment option discussions as she had taken on the role of the 'relayer of information' (Molly's description) to her father, Ben, who had a diagnosis of head and neck cancer and Alzheimer's disease. As Molly explained:

That treatment consultation was really fast for me 'cause they talk really, really fast (laughing). It's just fast and it's quick. This is a busy place for somebody with dementia. It all needs to be slowed down so much more.

The importance of pacing and giving time to others was also seen in Maria's (Case 9) explanation of the treatment decision-making process for her husband (Alistair) with metastatic cancer and stood in contrast to all other accounts in the data-set:

He [consultant oncologist] went through everything with Alistair and said 'you don't have to make a decision now, you can decide, you know, decide in your 
own good time because I realise this has come as a, as a big shock to you, you weren't expecting it, and I wasn't expecting to be recommending this to you'. That was a real help.

Maria went on to explain that the consultant repeating the information and cancer treatment options to her husband 'several times' was a good strategy, as well as simply sitting down next to him and losing the 'airs and graces'.

Time was also referred to by people who live with both dementia and cancer and family carers when discussing the format and quantity of cancer treatment information provision prior to treatment decision-making. As an illustration, Steve (Case 2) felt that he received enough verbal and take-home information (in the format of leaflets, for instance) about the various procedures for treating Brenda's colorectal cancer and found it helpful that his wife was present during all these discussions, although more in the shape of passive rather than active involvement. This rather lengthy extract from Steve's interview transcript best illustrates this conundrum:

She was there with the doctor here ... and she was, you know, part of that discussion. But again, you know, with her dementia, she was more interested about talking to the registrar, whether he was married or not. You know, did he have any children? Her mind wasn't ... the attention span and the focusing on something very, very important about someone's health just wasn't of much concern to her really. Although she was throughout the whole of the consultation, you know, there being informed of what the diagnosis was and the treatment plan. She was just not particularly, you know, focusing on that. She was more concerned with whether or not someone was married or what football team they liked and things like that, because of the dementia.

Participants also discussed the format of information that they received about treatment. Darren (Case 4) felt that he had to seek information out for himself to support the decision-making for his wife. Ben (Case 6), as a person with dementia and a recent diagnosis of head and neck cancer, felt that the cancer treatment information had to be offered in a variety of ways and formats with time given to ensure that he knew what was about to happen, or could happen, as he shared in this telling observation:

All that was spoken about I took in. But they [had] given us these leaflets; they had to be read for me ... 'cause I just can't do it and sometimes I know that but I just can't do it.

Interestingly, for Ben's daughter Molly, the length of time and speed of consultations were a concern as the contents had 'gone over my head a bit' and that she wanted more written information or the opportunity to have time to write things down herself, so that she could take her time and pass the information over to Ben in a way that he could 'take it all in'. This is an important point as Ben later clarified that his listening and understanding were situationally positioned 'in the moment' and that after a few minutes, he would simply be unable to recall 
what had been said. A state of affairs he also associated with the research interview that was being conducted at that moment in time. The exchange also speaks volumes about the central role of the family carer, their longitudinal and biographical knowledge of the person with dementia, and 'trial and error' expertise in effective communication approaches.

For some participants, decisions about the treatment options were immediate and clear-cut, as Victor (Case 8) shared in this straightforward summary:

You can get bombarded with irrelevant information ... and then it all becomes too much. I think to some extent I pushed all the negative things out-of-reach because the alternative is ... (pause) ... was worst. Yes, there were risks of having the treatment [stem-cell transplant] but there were risks in not having the treatment as well.

The role of the family carer was central to weighing up the cancer treatment options and was prompted by people living with dementia being aware that they would forget. It was time-precious in other words. As Victor went on to explain 'I felt as though if the doctor came to me and outlined what my problems were I'd forget that information'. Joseph (Case 5) also found the prospect of involving other supporters of the person living with dementia in the consultations helpful, as he shared:

I can forget a few things and not ask the correct questions ... it's good for somebody here (points towards nursing home staff office) to go with me. So having a person there makes a lot of sense. They can repeat everything that's been said ... back-up.

This need for the person living with cancer and dementia to protect themselves from the potential of mis-remembered - or forgotten - consultations about their cancer treatment was ever-present and caused heightened personal anxiety, particularly when focused on the risk of complications due to the cancer treatment. A potential solution to this dilemma was put forward by Victor (Case 8) when he suggested that a triadic consultation between (a) the person living with both dementia and cancer, (b) the health-care practitioner, and (c) the family carer should be considered 'the norm'. However, Victor expressed concern about how people living with both dementia and cancer, who lived alone, might cope should they find themselves 'in the same situation as me'.

One of the most difficult issues in weighing up the cancer treatment options came about when the interaction between symptoms of dementia on cancer treatment tolerance, and possible progression of the dementia, was discussed by participants. In the data-set, this manifested mainly in the conversations held by health-care practitioners and family carers, rather than by the person who lives with both dementia and cancer him- or herself. The potential for these interactions to occur in real-time significantly influenced the decision for Agatha (Case 10) not to have cancer treatment, as Agatha's son, Billy, described:

We could end up with somebody being maybe cured of a cancer but a lot worse on the dementia, so that's something we didn't want. Have an operation and they come out a lot worse it all seems so ... pointless. 
For both carer and oncology doctors in this case, quality of life was the most important decision-making factor for Agatha and that time, the best interests meeting was invaluable in successfully navigating through the decision-making process. However, for Billy, the decision not to treat left a lasting legacy as he shared in these reflections on his mother's best interests meeting:

I don't think she was too aware at the meeting. She was there but not really that involved. I don't think she understood what was going on really. She's not understood the full implications but did have a chance to comment if she wanted to. My mum did have a chance to say something, but I think she was messing with someone's hair at the time.

\section{Theme 4: Undergoing cancer treatment}

This final theme considers the experiences of the person living with dementia undergoing cancer treatment and what rose to the surface as important areas to consider. Alan (Case 7), for example, found it difficult to remember his cancer surgery although he was able to talk with more certainty about the health-care practitioners who attended to his post-surgical dressings. On the other hand, Alan made a plea for staff consistency in the process as all the 'swapping about' only added to his 'confusion' (Alan's word). Similar to the creative use of word association used by Joe (Case 3) to his mother (i.e. 'dirty throat' = cancer diagnosis) earlier in the article, he continued this technique in preparing his mother, Sally, for a set course of radiotherapy for her head and neck cancer as this rather moving extract from the data reveals:

They told her [Sally] what was going to happen. They did the various tests with us where they put little bits on her [mask fitting for radiotherapy treatment]. I can't remember, they had like a ... just put a bit of it, like a bit of this stuff on her face so she could feel what it was like, and then explained it, like a wet flannel, a warm flannel; so again that's ... that has sunk into my mum's head about a wet flannel. So all the treatment, when she had this mask on each day, the only one thing that she always remembers - if you ever ask her - she always remembers the wet flannel. She won't remember anything if you say 'Well, you're having this mask on' she'd be oblivious to it really, but if you say 'Mum, remember the flannel? You're having this flannel back' and then she'd remember. I don't know why that is, but obviously they had to sedate her with a tablet to calm her down to have it done.

For Joe, his mother's prolonged course of radiotherapy treatment (i.e. physically attending at a radiotherapy unit daily for four weeks) placed demands outside his usual caring role. Joe also had a job and he was thankful for the understanding and support of his employer in allowing him to be with his mother during her period of radiotherapy treatment.

Recalling major investigations and clinical procedures was also apparent in Alan's case (Case 7). For example, Alan found it difficult to remember the surgical procedure he had undergone to remove the skin cancer from his leg as this exchange with the researcher (LM) reveals: 
LM: I would like to ask you how you feel about your leg.

Alan: About what?

LM: Your leg.

Alan: What about it? Alright ... Why? What's up with it?

Receiving cancer treatment also caused significant difficulty for participants living with dementia in other ways. For example, Alistair (Case 9) was admitted as an emergency to different hospitals on two occasions part-way through his out-patient treatment. His wife, Maria, felt that this was due to the cancer treatment (chemotherapy) and its unanticipated side-effects. More importantly, perhaps, Maria viewed the experience as being 'very difficult for them both' as the initial hospital admission (secondary care) heightened her husband's confusion and levels of disorientation, as she explained:

He didn't know where he was and he didn't know who the people coming in were. He became terribly anxious and kept talking about things over and over. It was not a pleasant experience at all and in the end he came home probably before he should have done. I don't know ... I just couldn't bear him being in there anymore. So I brought him home with very little help, fast-track sort of thing, and they provided some carers to come.

Despite this, Maria reiterated how determined Alistair had been to eventually continue with chemotherapy treatment although, unfortunately, during the interview, Alistair was unable to reflect on the experience himself at that moment in time.

Continuing the theme of re-contextualising words and experiences so that people living with dementia were able to hold on and make sense of them, Sally (Case 3) named the hospital - in which she had been a patient for several months as 'the big white house'. Through this more familiar and domestic analogy, Joe spent time reflecting on whether or not his mother's radiotherapy treatment for cancer had exacerbated her symptoms of dementia, as he shared:

I don't know whether or not the drugs were having the impact on her as well; so it was the dementia with the impact of the drugs and all that together, having this change of the way my mum seemed. There's been a massive change with my mum dementia-wise.

Interestingly, the space created by undergoing treatment for the cancer gave an opportunity for family members to consider future options and if a return home for the person living with cancer and dementia was the best thing to do. This was neatly summarised by Joe when he said that his mother's cancer treatment was a 'blessing in disguise' as prior to the admission, he felt that it was best for his mother to go into a care home because of her dementia, but this had been [understandably] resisted. Now, with the cancer diagnosis and further advancement of his mother's dementia, the situation had progressed to a point where a future placement decision was seen as being in Sally's best interests. A similar 'best interests' decision was also reached for Brenda (Case 2) when she was to be discharged from hospital to a care home. This is not to be construed in any way at all as a 
criticism of the family and health/social care practitioners involved in either Sally or Brenda's situation, but, rather, as a reflection of the reality of the transition from National Health Service hospital bed to care home admission that is a reality for many people living with dementia in such circumstances.

Finally, the data identified a reflective component attached to undergoing cancer treatment for people living with dementia. As an illustration, Victor (Case 8) stated that whilst he is now feeling 'more well' after his stem-cell transplant, he was starting to consider the lasting implications of his dementia diagnosis on his everyday living and the experience he had just been through, as he stated:

Trouble is I don't remember much about all this. I'm still recovering so I'm more aware of problems ... I've come home and having to adapt and things in the house or re-learnt things which I'd forgotten about because I'm getting better I see what's wrong with me more. I've come home and having to adapt ... just trying to find where the light switches are.

In contrast, Joan (Case 4) said that she did not think she would like to go back to the hospital as she remembered the pain attached to her previous cancer-related experiences.

Finding ways of continuing to support an understanding of the procedures and processes that people who live with both dementia and cancer had endured seems such an important future step as the remembered experience of the person may be lost or its narrative meaning broken and/or fractured, as seen in shared extracts of data. Indeed, however the diagnostic and treatment stories are told by the person living with both dementia and cancer is an accurate record for its narrator and, as such, its meaning(s) should not be lost, diluted or discounted by families and/ or by health-care practitioners searching for 'the truth' of authentic representation. Arguably, locating ways to bridge that divide becomes a central goal of treatment in patients living with both dementia and cancer and in navigating and negotiating future treatment pathways.

\section{Discussion}

This study explored the lived experience of ten people living with dementia who had received a diagnosis of cancer and nine family carers. This included understanding how people who live with both dementia and cancer adjusted to their particular life circumstances and their specific cancer type, as well as developing a clearer insight into treatment decision-making. Of the ten participants living with both dementia and cancer in the study, only two were able to give informed consent to participate, the other eight requiring the involvement of a personal consultee to facilitate involvement, as per the study protocol (see also British Psychological Society, 2008). Whilst measuring the neuropsychological performance of participants was not part of the study design, as we relied instead on the clinical diagnosis of dementia already being made prior to the person being referred into the study, the number of consultee permissions required to conduct the interviews does suggest that issues of capacity framed the study analysis and influenced the outcomes of the work. 
Perhaps this was seen most vividly in the data-set when Billy (Case 10) described his mother's lack of engagement in her best interests meeting with the words 'she [Agatha] was messing with someone's hair at the time'. In other words, despite the seriousness of the multi-disciplinary team meeting and the focus on cancer treatment decision-making that was taking place, Agatha was simply unable to follow the prescribed social cues and engage in real-time with the events that were being discussed around - and about - her. As seen in Table 1, the outcome of the best interests meeting was for Agatha not to have any treatment for her cancer. This leaves an uncomfortable question: was this decision-making just?

Given the recent focus in the health and social policy literature on acknowledging the human rights of people living with dementia and in making transparent how people living with dementia are involved in decision-making (Mental Health Foundation, 2015), it may be that enhanced legal protection of the person with dementia moves to the forefront of ethical practice and clinical/treatment discussions building on the platform provided by the Mental Capacity Act (Department of Health, 2005). Moreover, people living with dementia themselves are actively pushing forward this rights-based agenda with active plans to nest their rights within the United Nations Convention on the Rights of Persons with Disabilities (CRPD), where the general principles of the Convention cover: respect for dignity, autonomy, freedom to make choices, independence; nondiscrimination (disability, gender, ethnicity, age); full participation and inclusion in society; respect for difference; acceptance of disability as part of human diversity; equality of opportunity; accessibility; and gender equality (Dementia Alliance International, 2016: 10). As such, and given the lack of published guidance, it would seem timely for future care pathways that address the needs of people who live with both dementia and cancer to be underpinned by these general principles. Moreover, whilst interventions to improve health-care staff training and education in treatment decision-making are available in the generic cancer-care literature (see e.g. Henoch et al., 2013), so far none has been identified in the area of living with a diagnosis of both dementia and cancer. This is despite the importance of the topic area seen in this and in recent studies and the need to enhance clinical practice and patient outcomes (see e.g. Courtier et al., 2016; Cook and McCarthy, 2018).

Whether the issues around capacity found in this study, albeit with a limited sample size, are indicative of a longer time to diagnosis of cancer when people also live with a dementia is speculative. However, a recent review of the dementia and cancer literature by McWilliams et al. (2018) identified two studies where the diagnosis of dementia influenced suspected cancer referrals and subsequent cancer treatment, or otherwise. One retrospective study investigated the influence of dementia on cancer referrals and found that out of a sample of 121 doctors, 33 per cent chose not to refer nursing home residents with suspected breast cancer for diagnostic testing and anti-cancer treatment - the primary reason cited was a diagnosis of end-stage dementia - yet only 41 per cent of decisions were discussed with the patient (Hamaker et al., 2012), perhaps underlining the importance of adopting the CRPD going forward. In the second study, recommendations for improving the care of patients with dementia and cancer were reported in a small qualitative study involving five health-care professionals. Interestingly, 
prime amongst these findings was the need to, firstly, provide support for family carers to enhance their involvement in decision-making and, secondly, to help ameliorate the family carer's emotional frustrations due to the communication difficulties often associated with dementia (Bartlett and Clarke, 2012); a situation that echoes the experiences of Billy (Case 10) and the majority of the family carers in this study. Additional research into the prevalence and lived experience of people who live with both dementia and cancer, and health professional's decision-making and management responses, particularly when the cancer is terminal, would appear necessary to help provide a more transparent local, regional and national picture.

Care-giving is a gendered experience and in the reported data-set, five men and four women comprised the study sample of family carers of people who live with both dementia and cancer. However, with some notable exceptions (see e.g. Mc Donnell and Ryan, 2013), gender has been largely overlooked in the dementia studies literature, especially in regards to care being provided at home (Erol et al., 2016). This omission has consequences. For example, in theme 1, reaching a diagnosis of cancer, the active social process of 'doing some detective work' appeared to eventually push Steve (Case 2) into finding out what caused the bleeding he regularly encountered in washing his wife's underwear. Steve had cared for his 60-year-old wife, Brenda, for a number of years following her diagnosis of Pick's disease, a type of frontotempotal dementia. Given Brenda's age it was, perhaps, fully understandable for Steve to rationalise that the blood in wife's underwear was due to menstruation, or the onset of the menopause or, in Steve's more perfunctory words, 'a woman's thing'.

The example above is a salient reminder that care is conducted at an emotional level but it is performed on, through and with the body. A few years ago, The International Longevity Centre - UK (ILC-UK) wrote a report entitled The Last Taboo and focused its discussions around sexual behaviour and intimacy in care homes (ILC-UK, 2011). Whilst such attention is important and necessary, the title of the report was unhelpful as there are many caring taboos in dementia (and outside this condition too of course) and one of them is in understanding more about the intimate care provided by men to their female spouse/partner with younger onset dementia during menstruation. The field in dementia care is awash with studies that address the importance of information in care, but it is not so plentiful in understanding the bodies of the person being cared for. Knowing more about the female body may, and we stress may, have helped Steve pathologise the encountered bleeding earlier in its onset and seek help sooner than the six months that it took him. This was not a recognition of the trajectory of dementia and the onset and management of behaviours that challenge (Moniz-Cook et al., 2017), for example, but, instead, it was one of recognising the early signs of anal (colorectal) cancer - a situation complicated by the fact that Brenda was simply unable to verbally share her concerns about her body with her husband. Individualising, and improving, the breadth and depth of information to family carers of people living with dementia to include the onset and signs of other long-terms conditions would be a suitable starting point to help improve the situation.

Linked into the above point is the need to develop information-giving support that is constructed from the language and meanings of care that are recognisable 
to those undergoing the process. This was seen in the data by Joe (Case 3) explaining his mother's cancer to her as a 'dirty throat' and then aligning his mother's course of radiotherapy treatment for her head and neck cancer to a 'wet flannel' so that she (Sally) could better understand the treatment that she was about to undergo. Staying with this family, it was also revealing that Sally, as a person living with both dementia and cancer, named the hospital where she had been an in-patient for cancer treatment for several months as 'the big white house'. By reflecting on these narrative constructions, these experiences are about making sense of the everyday and testing out, and adopting, communication strategies that worked for those involved, however painful the events. Arguably, it becomes necessary to leave space in professional caring practices for creativity and inventiveness in communication strategies between those who live with the condition and those closest to that person to help inform treatment approaches, decision-making and care documentation. As Richards (2007: 48) has noted, this everyday creativity is not trivial and 'represents a pervasive and dynamic way of being and knowing, and of encountering the world'. By embracing this 'little-c' approach to creativity (Kaufman and Beghetto, 2009; Bellass et al., 2019) it would, potentially, result in new ways of thinking about support, its meanings, embodiment and measurement, but driven from the life-world of those undergoing its impact; and that is the crucial point, especially when people living with dementia are attempting to make decisions and sense of the world around them through a limited palette of communication, spatial and remembering abilities.

Finally, to help advance understanding and public awareness, it would be important for people who live with both dementia and cancer to provide additional testimonies about their experience. As seen in the sample for this study, the ages of people who live with both dementia and cancer ranged from 39 to 93, but with the majority being over 70 years of age - which is reflective of the national picture. Finding ways to facilitate and empower such diverse ages and experiences is a daunting but, arguably, necessary challenge and one which can only help unlock opportunities to enhance the quality of life and wellbeing of people who live with both dementia and cancer. Such an approach would also assist in combating the stigma that continues to surround the experience of living with a dementia (ILC-UK, 2014). Successfully navigating these turbulent waters can only help to bridge the divide in understanding that undoubtedly exists at present.

\section{Study limitations}

There are three main study limitations. Firstly, the patient and family carer sample were recruited from a single cancer treatment hospital; therefore, it is not clear whether treatment decisions are sometimes made prior to referral to tertiary care. Similarly, it is not clear whether similar treatment decisions would have been reached/taken by other hospital sites should the authorship, with more resources, have been able to employ a broader recruitment strategy. Secondly, the cross-sectional nature of the study and its design limited the gaining of experiences and perspectives over time. Going forward, a more developed longitudinal study would provide a more detailed and robust understanding of lived experience that can be measured and plotted against significant time-points. Thirdly, there was 
limited ethnic diversity in the sample which is not representative of the area in which the data were collected.

\section{Conclusion}

In the most recent Dementia UK report (Alzheimer's Society, 2014a), it was noted under Action 12 that dementia research should receive a level of investment that matches the economic and human cost of the condition and made the telling observation that dementia costs the UK more than cancer, heart disease or diabetes. Despite this, the report pointed out that research funding for dementia in the UK was (at that time) $£ 74$ million a year, in comparison with the $£ 503$ million a year spent on cancer. However, one of the issues with such binary comparisons is just that, they are binary comparisons and focus on the tragedy of inequality rather than on the creativity of solutions. People who live with both dementia and cancer often do so with other long-term conditions (such as heart disease) and, if they do not, then they live with those two: the cancer that may (or may not) be curable and the dementia that is overwhelmingly not. However, the outcome of both experiences is similar: uncertainty and a future that is difficult to predict. As the narrative arc in this article has revealed, it is simply not possible to divide a person up into their separate diagnostic conditions. Lives and illnesses become intertwined and interrelated. Going forward, the research and practice field and, arguably, the research funding councils and condition-specific charities, need to come together to invest in the whole person, not just in one part in isolation from the rest - however worthy the cause. The lived experience of so many men and women living with a combination of enduring long-term conditions - and their family/support networks - need a breakout of common sense and consensus to occur, and soon. Only then, we would suggest, will real progress in evidence-generation and person-centred care and treatment be possible and those turbulent waters stilled.

Acknowledgements. The authors would like to thank sincerely the staff, patients and family involved in facilitating and taking part in this study. We would also like to thank Dr Jean Hennings for her assistance in data collection.

\section{References}

All-Party Parliamentary Group on Dementia (APPG) (2016) Dementia Rarely Travels Alone: Living with Dementia and Other Conditions. London: Alzheimer's Society.

Alzheimer's Disease International (ADI) (2009) World Alzheimer Report 2009. London: ADI.

Alzheimer's Disease International (ADI) (2011) World Alzheimer Report 2011: The Benefits of Early Diagnosis and Intervention. London: ADI.

Alzheimer's Disease International (ADI) (2013) World Alzheimer Report 2013: Journey of Caring - An Analysis of Long-term Care for Dementia. London: ADI.

Alzheimer's Disease International (ADI) (2016) World Alzheimer Report 2016: Improving Healthcare for People Living with Dementia. Coverage, Quality and Costs Now and in the Future. London: ADI.

Alzheimer's Research Trust (2010) Dementia 2010: The Economic Burden of Dementia and Associated Research Funding in the United Kingdom. Oxford: Alzheimer's Research Trust, University of Oxford.

Alzheimer's Society (2014a) Dementia UK: 2014 Edition. London: Alzheimer's Society.

Alzheimer's Society (2014b) Dementia 2014: Opportunity for Change. London: Alzheimer's Society.

Alzheimer's Society (2015) Dementia 2015: Aiming Higher to Transform Lives. London: Alzheimer's Society. 
Bartlett A and Clarke B (2012) An exploration of healthcare professionals' beliefs about caring for older people dying from cancer with a coincidental dementia. Dementia: The International Journal of Social Research and Practice 11, 559-565.

Bellass S, Balmer A, May V, Keady J, Buse C, Capstick AJ, Burke L, Bartlett R and Hodgson J (2019) Broadening the debate on creativity and dementia: a critical approach. Dementia: The International Journal of Social Research and Practice 18, 2799-2820.

Braun V and Clarke V (2006) Using thematic analysis in psychology. Qualitative Research in Psychology 3, 77-101.

Bridges J, Hughes J, Farrington N and Richardson A (2015) Cancer treatment decision-making processes for older patients with complex needs: a qualitative study. BMJ Open 5, e009674.

British Psychological Society (2008) Conducting Research with People Not Having the Capacity to Consent to Their Participation: A Practical Guide for Researchers. Leicester, UK: British Psychological Society.

Bunn F, Burn A-M, Goodman C, Rait G, Norton S, Robinson L, Schoeman J and Brayne C (2014) Comorbidity and dementia: a scoping review of the literature. BMC Medicine 12, 192.

Cahill S, Doran D and Watson M (2012) Guidelines for nursing homes delivering end-of-life care to residents with dementia across the island of Ireland. Quality in Ageing and Older Adults 13, 60-70.

Cancer Research UK (2017) Cancer Statistics. Available at http://www.cancerresearchuk.org/healthprofessional/cancer-statistics/risk.

Cook PS and McCarthy AL (2018) Cancer treatment decision making with/for older adults with dementia: the intersections of autonomy, capital, and power. Health Sociology Review 27, 184-198.

Courtier N, Milton R, King A, Tope R, Morgan S and Hopkinson J (2016) Cancer and dementia: an exploratory study of the experience of cancer treatment in people with dementia. Psycho-Oncology 25, 1079-1084.

Dementia Alliance International (2016) The Human Rights of People Living with Dementia: from Rhetoric to Reality. Available at https://www.dementiaallianceinternational.org/wp-content/uploads/2016/05/ Human-Rights-for-People-Living-with-Dementia-Rhetoric-to-Reality.pdf.

Department of Health (2005) Mental Capacity Act. London: HMSO.

Department of Health (2012) Prime Minister's Challenge on Dementia: Delivering Major Improvements in Dementia Care and Research by 2015. London: Department of Health.

Department of Health (2015) Prime Minister's Challenge on Dementia 2020. London: Department of Health.

Department of Health (2016) Prime Minister's Challenge on Dementia 2020 Implementation Plan. London: Department of Health.

Erol R, Brooker D and Peel E (2016) The impact of dementia on women internationally: an integrative review. Health Care for Women International 37, 1320-1341.

Hamaker ME, Hamelinck VC, van Munster BC, Bastiaannet E, Smorenburg CH, Achterberg WP, Liefers GJ and de Rooij SE (2012) Nonreferral of nursing home patients with suspected breast cancer. Journal of the American Medical Directors Association 13, 464-469.

Henoch I, Danielson E, Strang S, Browall M and Melin-Johansson C (2013) Training intervention for health care staff in the provision of existential support to patients with cancer: a randomized, controlled study. Journal of Pain Symptom Management 46, 785-794.

Hopkinson JB, Milton R, King A and Edwards D (2016) People with dementia: what is known about their experience of cancer treatment and cancer treatment outcomes? A systematic review. Psycho-Oncology 25, 1137-1146.

Jalil R, Ahmed M, Green JS and Sevdalis N (2013) Factors that can make an impact on decision-making and decision implementation in cancer multidisciplinary teams: an interview study of the provider perspective. International Journal of Surgery 11, 389-394.

Kaufman JC and Beghetto RA (2009) Beyond big and little: the four C model of creativity. Review of General Psychology 13, 1-12.

La Fontaine J, Jutlla K, Read K, Brooker D and Evans S (2016) The Experiences, Needs and Outcomes for Carers of People with Dementia: Literature Review. London: The Royal Surgical Aid Society. Available at http://www.thersas.org.uk/wp-content/uploads/2016/04/RSAS-ADS-Experiences-needs-outcomes-forcarers-of-people-with-dementia-Lit-review-2016.pdf.

Mc Donnell E and Ryan A (2013) Male caregiving in dementia: a review and commentary. Dementia: The International Journal of Social Research and Practice 12, 238-250. 
McWilliams L, Farrell C, Grande G, Keady J, Swarbrick C, Burgess L, Grande G, Bellhouse S and Yorke J (2018) Cancer-related information needs and treatment decision-making experiences of people with dementia: a multi-perspective qualitative study. BMJ Open 8, e020250.

McWilliams L, Farrell C, Grande G, Keady J, Swarbrick C and Yorke J (2018) A systematic review of the prevalence of comorbid cancer and dementia and its implications for cancer-related care. Aging and Mental Health 22, 1254-1271.

Mental Health Foundation (2015) Dementia, Rights and the Social Model of Disability. London: Mental Health Foundation.

Moniz-Cook E, Hart C, Woods B, Whitaker C, James I, Russell I, Tudor Edwards R, Hilton A, Orrell M, Campion P, Stokes G, Jones RSP, Bird M, Poland F and Manthorpe J (2017) Challenge Demcare: Management of Challenging Behaviour in Dementia at Home and in Care Homes - Development, Evaluation and Implementation of an Online Individualised Intervention for Care Homes; and a Cohort Study of Specialist Community Mental Health Care for Families (Final report). London: National Institute for Health Research.

Nolan MR, Grant G and Keady J (1996) Understanding Family Care: A Multidimensional Model of Caring and Coping. Buckingham, UK: Open University Press.

Richards R (2007) Everyday creativity: our hidden potential. In Richards R (ed.), Everyday Creativity and New Forms of Human Nature: Psychological, and Spiritual Perspectives. Washington, DC: American Psychological Association, pp. 25-53.

Smebye KL, Kirkevold M and Engedal K (2012) How do persons with dementia participate in decision making related to health and daily care? A multi-case study. BMC Health Services Research 2, 241-253.

Taghizadeh LA and Österholm JH (2014) How are decisions on care services for people with dementia made and experienced? A systematic review and qualitative synthesis of recent empirical findings. International Psychogeriatrics 26, 1849-1862.

The International Longevity Centre - UK (ILC-UK) (2011) The Last Taboo: A Guide to Dementia, Sexuality, Intimacy and Sexual Behaviour in Care Homes. London: ILC-UK. Available at http://www. ilcuk.org.uk/images/uploads/publication-pdfs/pdf_pdf_184.pdf.

The International Longevity Centre - UK (ILC-UK) (2014) A Compendium of Essays: New Perspectives and Approaches to Understanding Dementia and Stigma. London: ILC-UK. Available at http://www. ilcuk.org.uk/images/uploads/publication-pdfs/Compendium_Dementia.pdf.

Trachsel M, Hermann $\mathbf{H}$ and Biller-Andorno N (2015) Cognitive fluctuations as a challenge for the assessment of decision-making capacity in patients with dementia. American Journal of Alzheimer's Disease \& Other Dementias 30, 360-363.

Witham G, Haigh C and Foy S (2014) The challenges of health professionals in meeting the needs of vulnerable patients undergoing chemotherapy: a focus group study. Journal of Clinical Nursing 23, 2844-2853.

World Health Organization (2016) International Statistical Classification of Diseases and Related Health Problems 10th Revision (ICD-10) - WHO Version for 2016. Available at http://apps.who.int/ classifications/icd10/browse/2016/en\#/F00.

Cite this article: McWilliams L, Swarbrick C, Yorke J, Burgess L, Farrell C, Grande G, Bellhouse S, Keady J (2020). Bridging the divide: the adjustment and decision-making experiences of people with dementia living with a recent diagnosis of cancer and its impact on family carers. Ageing \& Society 40, 944-965. https:// doi.org/10.1017/S0144686X18001411 